\title{
UNA POLÍTICA PÚBLICA PARA LA OPTIMIZAGIÓN DE LA CALIDAD DE LA MEDIACIÓN FAMILIAR EN LATINOAMÉRICA*
}

\author{
A PUBLIC POLICY FOR OPTIMIZATION OF THE QUALITY \\ OF FAMILY MEDIATION IN LATIN AMERICA
}

\section{Isabel Ximena GONZÁLEZ RAMÍREZ**}

\section{Bastián Cuevas Campos***}

RESUMEN: El presente artículo trata de una política pública que utiliza una validada metodología empírica para optimización de la calidad de los servicios de mediación familiar que presta el Estado de Chile, como modelo a seguir para los países de Latinoamérica. Ello se ha venido implementando durante los últimos siete años, mediante investigaciones experimentales que sirven para la evaluación y formación de los mediadores. El uso de esta metodología cualitativa y cuantitativa ha ido mejorando sus procedimientos e instrumentos de medición de la calidad año con año, permitiendo al Estado chileno ofrecer soluciones sustenta-
ABSTRACT: This article deals with a public policy that uses a validated empirical methodology to optimize the quality of family mediation services provided by the State of Chile, which is a role model for Latin American countries. Experience that has been implemented, during the last seven years, through experimental research that serves for the evaluation and training of mediators. The use of this qualitative and quantitative methodology, has been improving its procedures and instruments of quality measurement year by year, allowing the Chilean State to offer sustainable solutions over time through high quality mediation processes, which evaluates the use of techniques in each of the components that make up each stage of the mediation process.

* Recibido el 20 de enero de 2020; aprobado el 12 de octubre de 2020.

Investigación realizada por el Centro de Mediación de la Universidad Central de Chile en 2018 y 2019.

** ORCID 0000-0001-6845-8198. Abogada Pontificia Universidad Católica de Chile, Doctora en Derecho Universidad de Buenos Aires y Docente Asociada Regular Derecho Penal, Facultad de Derecho y Humanidades Universidad Central, Mediadora de la Cámara de Comercio. Correo electrónico ogonzalezr@ucentral.cl. **** ORCID 0000-0002-9796-1750. Sociólogo, Magister (c) en Docencia para la Educación Superior de la Universidad Central de Chile, Coordinador de Carreras Técnicas, docente titular Carreras Técnicas. Correo electrónico bastian.cuevas. campos@gmail.com.

Boletín Mexicano de Derecho Comparado, nueva serie, año LIII, núm. 158, mayo-agosto de 2020, pp. 651-684. 
bles en el tiempo por medio de procesos de mediación de alta calidad, que evalúan el uso de técnicas en cada uno de los componentes que integran cada etapa del proceso de mediación.

Palabras claves: política pública, metodología, calidad, mediación familiar.
Keyzords: public policy, methodology, quality, family mediation.

SUMARIO: I. Introducción. II. Algunos antecedentes sobre la supervisión de la calidad de la mediación familiar en Iberoamérica. III. Política pública sobre la calidad de la mediación familiar licitada en Chile. IV. Conclusiones. V. Bibliografia.

\section{INTRODUCGIÓN}

Este artículo trata sobre una política pública usada para abordar colaborativamente los conflictos jurídicos de familia en Chile. País donde se ha ocupado durante los últimos siete años, una innovadora metodología empírica, para la selección y evaluación de la calidad de los mediadores familiares licitados, que prestan servicios al Estado, implementada por medio de un proceso continuo de investigación (Gonzalez, Valdebenito y Fuentealba 2018), que sirve también como un desafío a los mediadores para mejorar la calidad de sus procesos de gestión colaborativa de estos conflictos y que es una buena práctica a seguir en Latinoamérica.

Para efectos de diseñar esta metodología de tipo cualitativa y cuantitativa, se ha usado un tipo de investigación denominada de desarrollo experimental, que consiste en aprovechar los conocimientos obtenidos de la investigación y experiencia práctica para poner en marcha nuevos procesos o sistemas para la mejora sustancial de los servicios existentes (Carvajal L. 2013).

"La calidad del servicio de mediación familiar, ha avanzado en forma progresiva en la última década, lo que se ha logrado a través de la aplicación de esta política pública de supervisión de la calidad en los procesos de mediación, la que se ha incorporado por medio de métodos objetivos, aplicados de forma sistemática y uniforme en todo el país" (González 2018). Permite la validación de este mecanismo y una percepción favorable de los usuarios sobre ella, respecto a la forma como se sintieron 
tratados, como mejoraron sus relaciones interpersonales entre las partes y resolvieron el conflicto, según los estudios de percepción de usuarios, realizados anualmente, el ultimo de CADEM 2017. ${ }^{1}$

Ahora bien, si comparamos las diversas aplicaciones de este sistema a lo largo de siete años consecutivos, es posible afirmar que los resultados del Índice General de la Evaluación de la calidad del proceso de mediación familiar (en adelante ECAME) se mantienen en calidad alta, con una tendencia al alza de los valores que alcanzan los mediadores familiares licitados en procesos de familia (González, Valdebenito y Fuentealba 2018). La última medición se concentra en calidad alta con un estándar nacional de $74 \%$, el que baja en relación a la medición anterior, lo que se explica dado que el número de evaluados es casi el doble (el año 2013 aplicado a 270 mediadores, obtiene un puntaje medio de 68 puntos ECAME; en 2016, aplicado a 243 mediadores, con promedio ECAME 79, y en 2018 a 504 mediadores, promedio ECAME 74) (González y Cuevas 2020).

En 2004 con la Ley 19.968 que crea los Tribunales de Familia, se incorpora la mediación en forma legal en Chile, la que con la entrada en vigencia de la Ley 20.286 de 2008, se hace previa y obligatoria para las partes el intentar antes de la interposición de una acción judicial en materia de familia referida a los alimentos, cuidado personal y relación directa y regular$^{2}$ (González, Valdebenito y Fuenteaba 2018), un acuerdo por medio de un proceso de mediación (Stein 2015), la que también opera en el marco de una acción de divorcio o separación judicial, establecidas en el artículo 106 de esta ley (Acuña 2011).

Sin embargo, los primeros años de su implementación, existía una mala percepción de la calidad de los servicios que prestaban los media-

1 CADEM, diciembre 2017, "Diseño, aplicación y análisis de Encuesta de Satisfacción de Usuarios/as del Sistema Nacional de Mediación Familiar". Disponible en https://wrere. mediacionchile.cl/media/2017/03/Informe-Final-Mediaci\%C3\%B3n-Familiar-2016_CADEM_ VF.pdf.

2 La mediación familiar ha sido definida como: "Un proceso de resolución de conflictos regulado por principios dogmáticos y legales en el cual, un(a) mediador(a) imparcial, genera comunicación efectiva y constructiva entre las partes y promueve la participación igualitaria, autónoma y responsable en la búsqueda de soluciones a conflictos familiares, facilitando la generación de acuerdos construidos desde las partes interesadas con recíproca satisfacción subjetiva". Informe Final definitivo, Auditoría externa para la evaluación de la calidad de los procesos de mediación familiar, Centro de Estudios y Asistencia Legislativa de la Pontificia Universidad Católica de Valparaíso, 2011. 
dores licitados, tanto desde la ciudadanía como de los abogados y jueces (Muñoz 2015). Razón por la que el Ministerio de Justicia y Derechos Humanos de Chile, llevó a cabo en 2011, por la Universidad Católica de Valparaíso y del 2012 hasta la fecha, por la Facultad de Derecho de la Universidad Central de Chile, siete estudios, que contienen investigaciones aplicadas y experimentales para la evaluación y supervisión de la calidad en los servicios de los mediadores familiares licitados, se creó para estos efectos los instrumentos necesarios para medir y comparar los distintos componentes propios de la calidad en los procesos de mediación familiar de cada mediador, centro de mediación y región del país, retroalimentando la gestión de sus actores, con el propósito de mejorar la calidad del servicio que se otorga a la ciudadanía (González, Valdebenito y Fuentealba 2018).

Sistema que actualmente no sólo se ocupa para la supervisión sino también para la selección de los nuevos mediadores, que prestan estos servicios al país por los próximos cuatro años.

Los resultados de las evaluaciones han permitido retroalimentar a sus operadores y orientar espacios de formación focalizados por zonas del país, según las carencias que se manifiestan en cada localidad. Capacitaciones que se han realizado mediante talleres participativos de aprendizaje entre pares, compartiendo buenas prácticas mediadoras con una modalidad de aprendizaje-acción (González, Valdebenito y Fuentealba 2018).

En este contexto y considerando que la mediación en América Latina es un mecanismo de política pública importante en materia de derecho de familia (Preyer 2016), requiere implementarse metodologías para supervisar y mejorar en forma continua la calidad del servicio que se presta y para la selección de los mediadores que deben guiar estos procesos, razón por lo que surge el siguiente planteamiento del problema: ¿cuáles son los principales elementos que sostienen la política pública en Chile, para evaluar la calidad de los servicios de mediación licitada en materia de familia, por medio de la aplicación de una metodología de desarrollo experimental, que componentes mide y cuáles son sus resultados?

Este estudio se plantea una hipótesis en los siguientes términos: los principales elementos de una política pública para mejorar la calidad de los servicios de mediación licitada en materia de familia, son el mantener un sistema permanente y uniforme de selección y evaluación de la calidad de los mediadores que prestan servicios públicos, por medio de un 
sistema participativo, centrado en los componentes más relevantes de este mecanismo, como son la legitimación de la mediación, con dimensiones propias de la comunicación, participación y gestión del conflicto y el componente de acogida y contención de emociones, que son los que presentan mayor complejidad en su desarrollo (Gonzalez y Cuevas 2020). Por medio de la sostenida aplicación de una metodología de desarrollo experimental cuyos procesos e instrumentos están en permanente actualización, con un sistema de enseñanza aprendizaje entre pares (Gonzalez, Valdebenito y Fuetealba 2018), que ha entregado resultados que permiten expectativas optimistas respecto a la mejora continua del proceso de mediación familiar en el ámbito público.

El objetivo de este artículo es analizar los principales parámetros de la política pública, los componentes que son evaluados para medir la calidad de los servicios de mediación familiar licitada en Chile y sus resultados, los que pueden considerarse dignos de ser utilizados como modelo en otros países de Latinoamérica.

Para lograr este objetivo se utilizó un diseño exploratorio con una metodología empírica, que da cuenta de los resultados de dos investigaciones realizadas en 2018, por el Ministerio de Justicia y el Centro de Mediación y Arbitraje de la Universidad Central de Chile, a todo el universo de mediadores familiares licitados en Chile, que dan claridad acerca de los componentes de los procesos de mediación familia más complejos de aplicar, en las distintas etapas y mediante el uso de técnicas avanzadas y propias de este mecanismo.

La estructura de este artículo se inicia con un apartado que describe someramente la política pública empleada en algunos países de Latinoamérica y en Chile para mejorar la calidad de la mediación familiar licitada. Luego continúa con los más importantes componentes que se miden en el instrumento utilizado para la evaluación de la calidad de la mediación familiar y termina dando cuenta de los resultados que se han obtenido en los ítems seleccionados como los más relevantes en el proceso de medición de la calidad de la mediación y termina con algunas conclusiones obtenidas de este estudio.

Finalmente, podemos señalar que este estudio es relevante, ya que da a conocer una interesante política pública que aplica en forma sostenida una metodología validada para evaluar y mejorar la calidad de los procesos de mediación familiares en el país y seleccionar a los mejores profesionales 
para realizar esta función pública, se analizan los componentes que forman parte de las etapas del proceso de este mecanismo. Estudio que puede servir como una etapa previa a otras investigaciones que puedan abordar su aplicación en otras latitudes de Latinoamérica.

\section{Algunos ANTEGEDENTES SOBRE LA SUPERVISIÓN DE LA CALIDAD DE LA MEDIACIÓN FAMILIAR EN IBEROAMÉRICA}

El análisis del estado arte en materia de supervisión y mejoramiento de la calidad en mediación familiar, da cuenta de que en Iberoamérica se conocen pocas experiencias en profundidad sobre la materia, especialmente que cuenten con sistemas estandarizados de evaluación de la calidad aplicados en el ámbito nacional en forma permanente (González 2018).

Ahora bien, sólo a modo de ejemplo, podemos señalar que en países como Argentina (González 2018), su regulación normativa alude a competencias que deben presentar los mediadores familiares, tales como el saber escuchar, tener una capacitación específica y entrenamiento en el tratamiento interdisciplinario de una problemática familiar, hábil en la comunicación, neutral, imparcial, actuar confidencial y éticamente y ser creativo, entre otras (García y Aguilera 2009). También en ese país ha implementado el Estado, por medio de las Defensorías del Pueblo, un sistema de acompañamiento interno a los equipos de mediadores públicos, destinado a fortalecer las competencias jurídicas de atención y el trabajo en equipos multidisciplinarios, para la atención sistémica e integrada de las causas recibidas (González, Valdebenito y Fuentealba 2018).

También en Brasil (Resolución 125 de 2010), donde recientemente se ha implementado el sistema de mediación anexo a los tribunales, la supervisión de la atención de los casos mediados está integrado desde el inicio como mecanismo de control y de aseguramiento de la calidad, al incorporarlo como horas de trabajo de co-mediación y de observación por expertos en sala, sin contar hasta ahora con estudios sobre los instrumentos utilizados (González, Valdebenito y Fuentealba 2018).

Por otra parte, en el caso de Guatemala (González, Valdebenito y Fuentealba 2018), existe una investigación que versa sobre la observación de casos de mediación y aplicación de una guía de observación que da cuenta de la calidad de procesos de mediación en 14 casos observados, du- 
rante un lapso de 20 días aproximadamente, la que arroja como resultado un parcial cumplimiento de las funciones mediadoras, recomendando la incorporación de sistemas de monitoreo y evaluación efectiva y permanentes (Fernández y Colt 2013).

En España, se realizan procesos de supervisión que contemplan trabajo clínico y análisis de casos (Migrainfo 2008), en materia de mediación comunitaria más que en el área familiar. También en diversas comunidades autónomas de este país, tales como Cataluña, Valencia, Galicia, entre otras, se ha regulado la mediación por recomendación del Consejo de Europa a partir del 16 de septiembre de 1986, como vía alternativa para prevenir y reducir la excesiva carga de los tribunales de justicia (Lopez 2012), y no como una mejor manera de abordar un conflicto de familia (González 2018) lo que nos hace plantearnos la relevancia que se le da a la calidad en dichos procesos.

Finalmente, el cuestionamiento acerca de la calidad de los procesos de mediación en Latinoamérica se ha iniciado con reflexiones teóricas, como es el caso de la de Brandoni, quien plantea interrogantes como: ¿qué mecanismos pueden utilizarse para cuidar y mejorar la calidad de la tarea del mediador?, ¿cómo se establecen los estándares de calidad?, ¿quién y cómo se mide la calidad del servicio de mediación y la tarea de los mediadores? (Brandoni 2011), presenta propuestas en líneas generales, apropiadas para que cada uno de los operadores de justicia, diseñen e implementen mecanismos acordes a su ejercicio profesional, lo que da cuenta de una carencia de sistematicidad en el abordaje de la calidad de aquellos procesos de solución colaborativa de conflictos jurídicos familiares en gran parte de los países (González, Valdebenito y Fuentealba 2018).

\section{POLÍTICA PÚBLICA SOBRE LA GALIDAD DE LA MEDIACIÓN FAMILIAR LICITADA EN CHILE}

En Chile, en 2004 con la Ley 19.968, al incorporarse la mediación en los procesos de familia, se creó un Sistema Nacional de Mediación licitado, para garantizar la calidad del ejercicio profesional de los mediadores, cuya gestión y administración corresponde a la Unidad de Mediación del Ministerio de Justicia y Derechos Humanos — en adelante MINJU(González, Valdebenito y Fuentealba 2018). 
Con este objeto también se crea un Registro de Mediadores Familiares, en donde deben inscribirse con requisitos de profesión, formación teórica y práctica en mediación y una oficina adecuada, los profesionales que quieran ejercer como mediadores en el ámbito de familia (González, Valdebenito y Fuentealba 2018).

Para seleccionar a los mediadores licitados, el Ministerio de Justicia ha establecido, además de su inscripción en el Registro de Mediadores, pruebas de conocimientos aplicadas a nivel nacional y un examen psícolaboral, para evaluar que el perfil del mediador (González 2018), su inteligencia emocional, su equilibrio emocional y características de personalidad sean acordes para desempeñar esta tarea.

Para garantizar una adecuada cobertura de estos servicios en el ámbito nacional, desde 2006 a la fecha, en Chile, ha venido operando un sistema de licitaciones destinadas a la contratación de los servicios de mediadores familiares (González, Valdebenito y Fuentealba 2018), los que otorgan servicios al 87\% de la población en esta materia (Correa 2014, 119).

Junto con este conjunto de acciones técnicas, se han sumado otros procesos destinadas a la supervisión de la calidad del servicio prestado por los mediadores licitados, con el fin de evaluarlos y perfeccionarlos, con miras a alcanzar estándares adecuados de calidad (Correa 2014, 119).

Entendemos por mediación familiar en este estudio, el concepto de John Rawls: "Un proceso de resolución de conflictos regulado por principios dogmáticos y legales en el cual, un(a) mediador (a) imparcial, genera comunicación efectiva y constructiva entre las partes y promueve la participación igualitaria, autónoma y responsable en la búsqueda de soluciones a conflictos familiares, facilitando la generación de acuerdos construidos desde las partes interesadas con recíproca satisfacción subjetiva" (Rawls 2002).

Adicionalmente, comprendemos la calidad del proceso de mediación, como la ha definido González, Valdebenito y Fuentealba (2018) como evaluación hecha por las partes durante la prestación del servicio, valorando la calidad como resultado, juzgada por el consumidor después de la prestación del servicio. Se refiere a la evaluación de competencias y destrezas del mediador, que permitan obtener resultados que dan mayor satisfacción final a los usuarios y operadores (González 2018). Guyo control según algunos, es difícil de determinar con parámetros cuantitativos y 
estadísticos (Aguilar 1994). Y por calidad técnica, la formación y la acreditación profesional y funcional respeto a las normas del proceso a códigos deontológicos y éticos (Lehtinen, U. y Lehtinen J. R. 1982).

Esta política pública en Chile se inicia a propósito de que existían, desde 2004, dudas acerca de la calidad de los servicios de mediación familiar licitada que ofrecía el Estado. ${ }^{3}$ Lo que cobra especial relevancia cuando en 2008 con la Ley 20.286 se modificó con la Ley 19.968, convirtiendo este mecanismo en previo y obligatorio para las partes, antes de la interposición de una acción judicial referida a los alimentos, cuidado personal y relación directa y regular, cuyo acuerdo aprobado por el Tribunal de Familia es equivalente jurisdiccional a una sentencia (García y Aguilera 2009), con lo que este proceso compromete no sólo los servicios del Poder Ejecutivo en el país, sino también los del judicial (González 2018).

Así, en 2011 se comenzó a aplicar en todo Chile una metodología aplicada para el logro de un sistema permanente de supervisión clínica y mejoramiento continuo de la calidad de la mediación familiar.

Metodología de carácter cuantitativa y cualitativa denominada: "Evaluación de la calidad del proceso de mediación familiar" (ECAME). Para lo que se elabora y prueba este instrumento denominado de la misma manera.

La pauta llamada ECAME permite valorar conductas y competencias definidas a priori, que deben ser realizadas en el proceso de mediación por los mediadores licitados, la que se logra mediante una observación participante (Stein 2015).

Dicha supervisión, es aplicada de manera uniforme e igualitaria a todos los evaluados, la que es seguida de una autoevaluación del mediador, retroalimentación del supervisor y la entrega posterior de un completo informe sobre su proceso de mediación videograbado, para que el mediador observe su desempeño y finalmente un taller participativo (González 2018), útil para uniformar competencias y fortalecer algunas falencias observadas con cápsulas audiovisuales en que se transmiten buenas prácticas mediadoras (Muñoz 2015).

3 Universidad de Concepción, Estudio Calidad del Servicio de Mediación Licitado por el Ministerio de Justicia. http://wreremediacionchile.cl/MinfusPubl/Sitio/pub_estadisticas. aspx (consultado en enero de 2018). Véase http://mediacionchile.cl, donde se encuentran las distintas auditorías de evaluación de satisfacción del usuario en mediación, realizadas desde el 2006 en adelante. 
Luego de efectuada la supervisión se sistematizan los resultados obtenidos, construyendo informes evaluativos por cada zona, que son analizados estadísticamente y valorados cualitativamente mediante una metodología de carácter mixta, que interpreta los resultados de la supervisión, seleccionándolos por género, mediador, centro de mediación, zona de licitación y por región y un Índice de Gestión de la Calidad de la Mediación, total y por componente, compuestos por ítem que describen las competencias que se espera se desplieguen por los mediadores licitados (González, Valdebenito y Fuentealba 2018). También, se incorpora un enfoque cualitativo en el tratamiento de los diversos aspectos observados en la supervisión, en sus distintas etapas de trabajo clínico (González 2018).

Junto a los análisis ya mencionados, se generó una variable ordinal de resultado del Índice de Gestión de la Calidad de la Mediación (IGCM). Para la correlación entre las variables dependientes y tamaño de centro (González, Valdebenito y Fuentealba 2018), se utilizó el coeficiente Rho de Spearman, adecuado para establecer el grado de correlación entre una variable cuantitativa continua (índices) y una variable ordinal (porte centro) (Hernández 2003).

Finalmente, todos los años se realiza una propuesta de mejoramiento del instrumento y del proceso ECAME, para lo que se sistematizan las opiniones de los supervisores sobre el instrumento y procedimiento de evaluación y sobre la práctica mediadora, lo que se entrega en un informe al MINJU en el que se consolida la información recogida, analizada y procesada durante la investigación aplicada, incorpora los resultados a nivel nacional, el IGCM y las conclusiones (González 2018) y (González, Valdebenito y Fuentealba 2018).

\section{Método}

El ECAME es una metodología compleja, que evalúa el proceso de mediación considerando los componentes de proceso, en sus aspectos técnicos y éticos, con un instrumento validado metodológicamente y por expertos, que es posible de aplicar en cualquier etapa del proceso de mediación e implementar en forma masiva a todos los mediadores en ejercicio, los que participan en este proceso por un periodo de 120 minutos (González 2018 y González, Valdebenito y Fuentealba 2018) siendo evaluados 
por un equipo interdisciplinario de mediadores expertos, tanto del sector privado como del público, que actúan como supervisores (Beloff 2010).

\section{Participantes}

La última aplicación de la metodología ECAME que da origen a la presenta investigación se desarrolló durante 2018, en la cual 505 mediadores y mediadoras en total rindieron la evaluación, como una de las etapas del proceso de selección, que se realiza para desempeñarse como mediador licitado, los próximos cuatro años, obteniendo un promedio general de 74,29 de puntaje.

\section{Instrumento}

La metodología empleada en el estudio fue de carácter cuantitativa a partir del instrumento denominado Evaluación de la Calidad de la Mediación, el cual representa un mecanismos sistemático y validado, el cual permite calcular un índice de calidad del mediador/a, por medio de la observación in situ de tres especialistas externos.

Esta metodología define las conductas y los indicadores esperados para una medicación de calidad, el cual corresponde a una pauta de evaluación mediante las obversaciones de aplicaciones simuladas de sesiones de mediación (González, Valdebenito y Fuentealba 2018).

El instrumento contiene tres componentes con distintos tamaños y pesos relativos, todos correlacionados y con alta consistencia entre sí, los que suman en total 26 ítems. Los tres componentes que integran el instrumento ECAME no se focalizan en modelos de mediación determinados, con el objeto de dar libertad a los profesionales mediadores para elegir su propio estilo y utilizar el modelo más adecuado al caso concreto en que deben intervenir (González, 2018) y (González, Valdebenito y Fuentealba 2018). Dichos elementos corresponden a (Informe Ministerio de Justicia 2015) y (González, Valdebenito y Fuentealba 2018).

Componente número 1 , proceso de mediación: concentra un total de 18 ítems, que se agrupan en función de conductas y habilidades que despliega el mediador(a) en la sala de mediación, que dan cuenta del proceso de atención, y se divide en cuatro dimensiones, las cuales son: 
a) Dimensión legitimidad de la mediación, esto dice relación con que el mediador explique correctamente que es la mediación, las características que validan a este mecanismo para resolver conflictos, el rol del mediador en el proceso, los principios que la sustentan (voluntariedad, imparcialidad, equilibrio de poderes, interés superior del niño(a) y adolescente y las condiciones de contexto (tales como indicar que es adecuado obtener asesoría jurídica, normas de comportamiento en la sesión) y alguna información jurídica que la regulan (como temas relativos a los alimentos provisorios, prohibición de mediar cuando hay acciones de violencia intrafamiliar vigentes, entre otras (García y Aguilera 2009).

b) Dimensión de habilidades comunicativas, evalúa la capacidad del mediador de establecer un clima de confianza y un puente de comunicación entre las partes, usando técnicas como el lenguaje analógico, expresar mensajes en primera persona, el parafraseo que ayuda a entender e interpretar los hechos y actos de las personas de una forma distinta a la que habían venido comunicando hasta ahora, eliminando descalificaciones, agresiones, sustantivaciones, y generalizaciones que impedía encontrar soluciones a los conflictos, los resúmenes que dan contexto a las peticiones de las partes y orientan el estado de avance del proceso. Esto ayudado con otras técnicas como preguntas cerradas, abiertas, indagatorias, reflexivas, hipotéticas y circulares, para abrir el conflicto e ir reconociendo al otro, transformando las posiciones en necesidades de las partes.

c) Dimensión de participación, que pretende crear un clima de confianza, equilibrar el poder y lograr igualdad entre las partes, por medio de una intervención equilibrada de estas, que le permita al mediador dar circularidad al conflicto, mediante técnicas como preguntas circulares, haciendo ponerse a las partes en el lugar de la otra, de hijos o terceros.

d) Dimensión de gestión, que pretende gestionar el conflicto entre las partes, distinguiendo claramente cuáles son los puntos de acuerdo y aquellos en que debe trabajarse, ya transformadas las posturas en necesidades mutuas, ofreciendo a veces una historia alternativa y común a la que plantearon las partes por separado, usando técnica de recontextualización o reencuadre, ofreciendo otro ángulo y contexto para mirar el conflicto. 
Componente núm. 2, contención de emociones en los mediados: conductas o habilidades que despliega el mediador las referidas a la contención de las emociones, especialmente agresiones de corte psicológico y habilidad emocional (Jiménez 2011), el que utiliza técnicas como la identificación y expresión de la emoción y la re-significación de ésta, dándole un contexto, temporalidad y circunstancias en que se manifiesta, con el objeto de ser entendida adecuadamente y que la otra parte pueda empatizar con ella. Otra técnica muy importante es la legitimación que intenta que las partes se reconozcan mutuamente algunos valores, virtudes o actitudes personales, lo que crea un clima de entendimiento que facilita acuerdos (4 ítems).

Componente núm. 3, búsqueda de posibles acuerdos: se refiere a como el mediador va fortaleciendo la reflexión entre las partes para la posible toma de decisiones respecto del problema que les aqueja. Empleando técnicas como la lluvia de ideas, múltiples opciones, selección de opciones, y aplicar filtros a los acuerdos de las partes para que estos sean sustentables, mediante el uso de técnicas como: agente de realidad y abogado del diablo, entre otras (4 ítems).

En cada componente se incorporan algunos ítems de actitudes coherentes con las políticas públicas, ${ }^{4}$ al que corresponden 18 ítems y que abordan elementos como el enfoque de género (Lombardo 2003), aspectos de interculturalidad, identidad sexual, violencia intrafamiliar, presencia de los niños, niñas y adolescentes en la mediación (Villacampa 2012), co-parentalidad (Latrop 2013), y derechos de los niños, niñas y adolescentes (Barcia 2013), las que por su importancia y haber sido validados por expertos, se considera necesario incluirlos como variables, cuyo puntaje no se promedia con los componentes y pueden cambiarse con el tiempo conforme a las orientaciones de las políticas públicas determinadas por el MINJU.

4 En adelante ACPP. 
Esta revista forma parte del acervo de la Biblioteca Jurídica Virtual del Instituto de Investigaciones Jurídicas de la UNAM http://www.juridicas.unam.mx

EVALUACIÓN PRÁCTICA DE LOS MEDIADORES (PAUTA ECAME)

1. Datos de identificación del proceso y del mediador evaluado

Cada Informe ECAME deberá contener la información mínima del mediador evaluado y proceso supervisado que a continuación se indica:

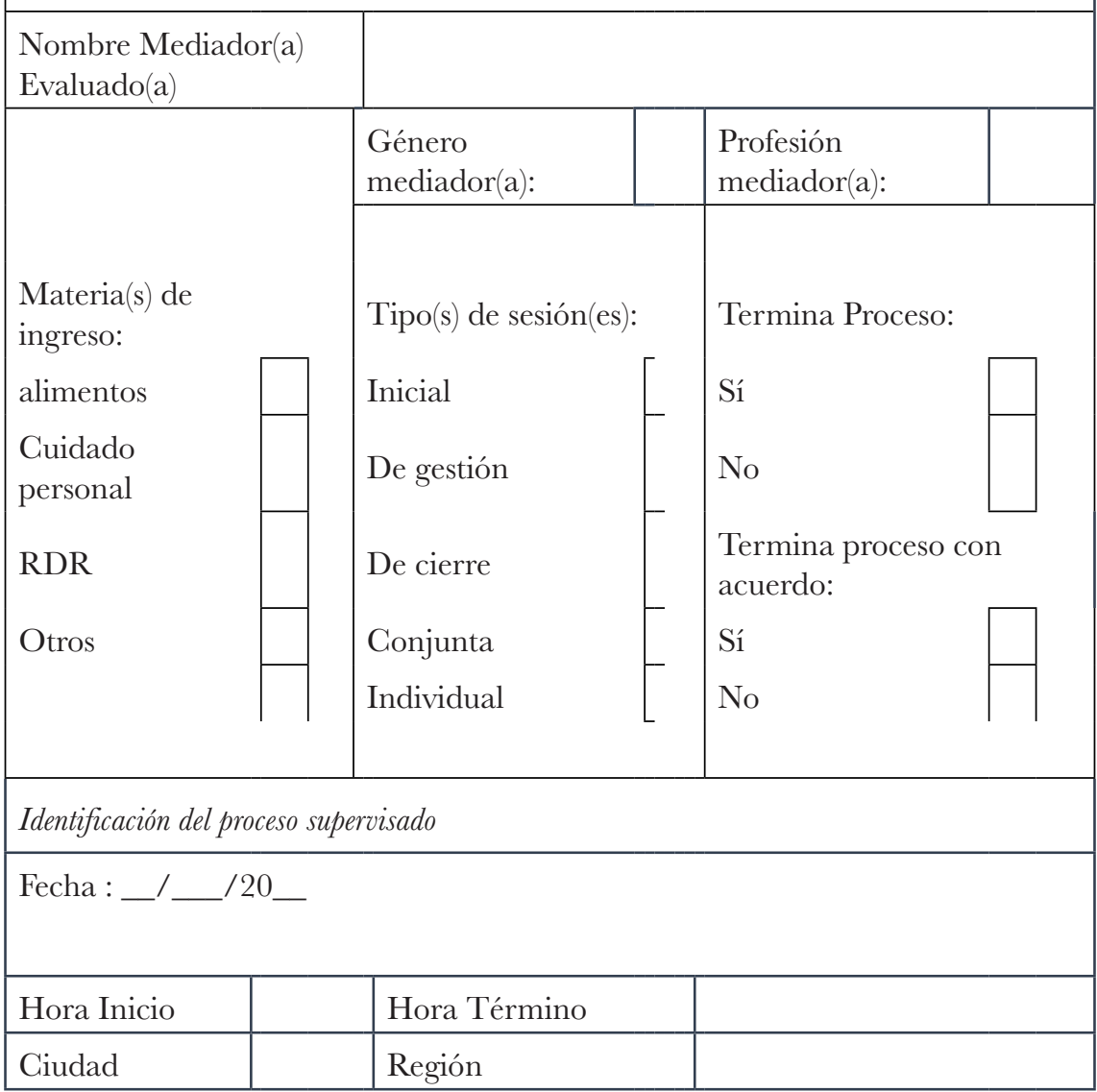

Esta obra está bajo una Licencia Creative Commons

Atribución-NoComercial-SinDerivar 4.0 Internacional, IIJ-UNAM.

Boletín Mexicano de Derecho Comparado, núm. 158, mayo-agosto de 2020, pp. 651-684. 


\section{Instrucciones de aplicación del Instrumento ECAME}

Pauta ECAME: Consta de un conjunto de ítems que se deben observar si están presentes durante toda la sesión de mediación en el desempeño del mediador/a quien se esté supervisando. Para ello, se debe marcar al costado de cada ítem, el casillero que mejor representa la presencia de la práctica observada en relación al contexto, conforme a la siguiente tabla.

Esta pauta será aplicada por el Comité EGAME, constituido para estos efectos, posteriormente a la videograbación de la simulación.

\begin{tabular}{|l|l|}
\hline Muy frecuente (MF) & $\begin{array}{l}\text { si está presente entre } \\
\text { el } 71 \text { y } 100 \% \text { de lo } \\
\text { requerido }\end{array}$ \\
\hline Frecuente $(\mathrm{F})$ & $\begin{array}{l}\text { si está presente entre } \\
\text { el } 51 \% \text { y } 70 \% \text { de lo } \\
\text { requerido }\end{array}$ \\
\hline Ocasional $(\mathrm{O})$ & $\begin{array}{l}\text { si está presente entre } \\
\text { el } 31 \text { y } 50 \% \text { de lo } \\
\text { requerido }\end{array}$ \\
\hline Muy ocasional $(\mathrm{MO})$ & $\begin{array}{l}\text { si está presente entre } \\
\text { el } 1 \text { y } 30 \% \text { de lo } \\
\text { requerido }\end{array}$ \\
\hline Ausencia (A) & $\begin{array}{l}\text { si no está presente } \\
(0 \%)\end{array}$ \\
\hline
\end{tabular}

\section{Composición Pauta ECAME}

La Pauta ECAME se compone de 44 ítems agrupados en tres componentes y Actitudes Coherentes con Políticas Publicas. Siendo esta su distribución

\begin{tabular}{|l|l|}
\hline Componente núm. 1 & 18 ítems \\
\hline Componente núm. 2 & 4 ítems \\
\hline Componente núm. 3 & 4 ítems \\
\hline $\begin{array}{l}\text { Actitudes coherentes con las } \\
\text { políticas públicas }\end{array}$ & 18 ítems \\
\hline
\end{tabular}


Esta revista forma parte del acervo de la Biblioteca Jurídica Virtual del Instituto de Investigaciones Jurídicas de la UNAM http://www.juridicas.unam.mx

DOI: http://dx.doi.org/10.22201/iij.24484873e.2020.158.15632

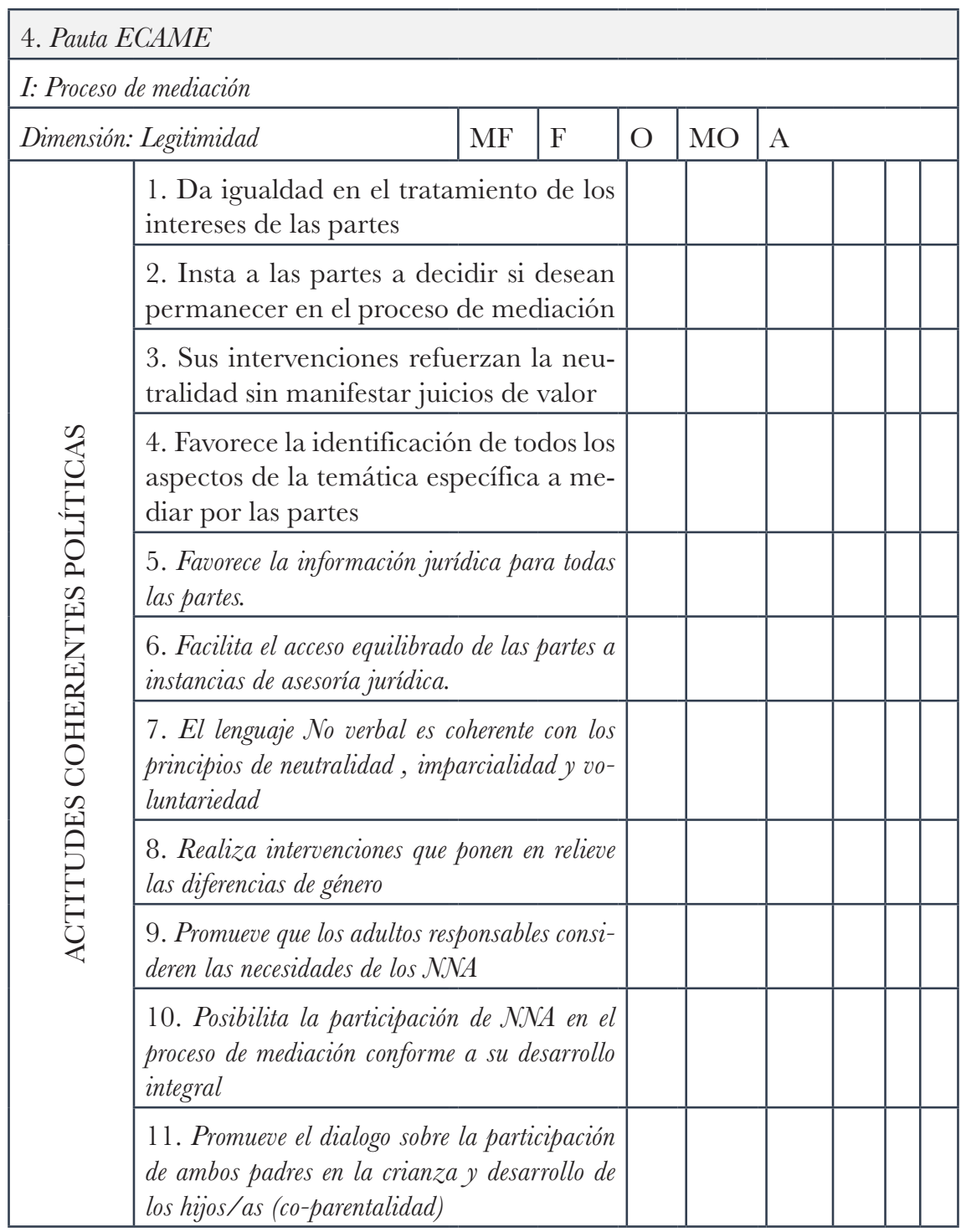

Esta obra está bajo una Licencia Creative Commons

Atribución-NoComercial-SinDerivar 4.0 Internacional, IIJ-UNAM.

Boletín Mexicano de Derecho Comparado, núm. 158, mayo-agosto de 2020, pp. 651-684. 
Esta revista forma parte del acervo de la Biblioteca Jurídica Virtual del Instituto de Investigaciones Jurídicas de la UNAM http://www.juridicas.unam.mx

\begin{tabular}{|l|l|l|l|l|l|l|}
\hline $\begin{array}{l}\text { 12. Aplica criterios establecidos en leyes y re- } \\
\text { glamentos que prohiben mediar en caso de que } \\
\text { exista VIF }\end{array}$ & & & & & & \\
\hline $\begin{array}{l}\text { 13. Facilita el conocimiento de las normas so- } \\
\text { bre alimentos provisorios. }\end{array}$ & & & & & & \\
\hline $\begin{array}{l}\text { 14. Trabaja conforme a la agenda construida } \\
\text { por las partes }\end{array}$ & & & & & & \\
\hline
\end{tabular}

\begin{tabular}{|l|l|l|l|l|l|}
\hline Dimensión: Comunicación & MF & F & O & MO & A \\
\hline
\end{tabular}

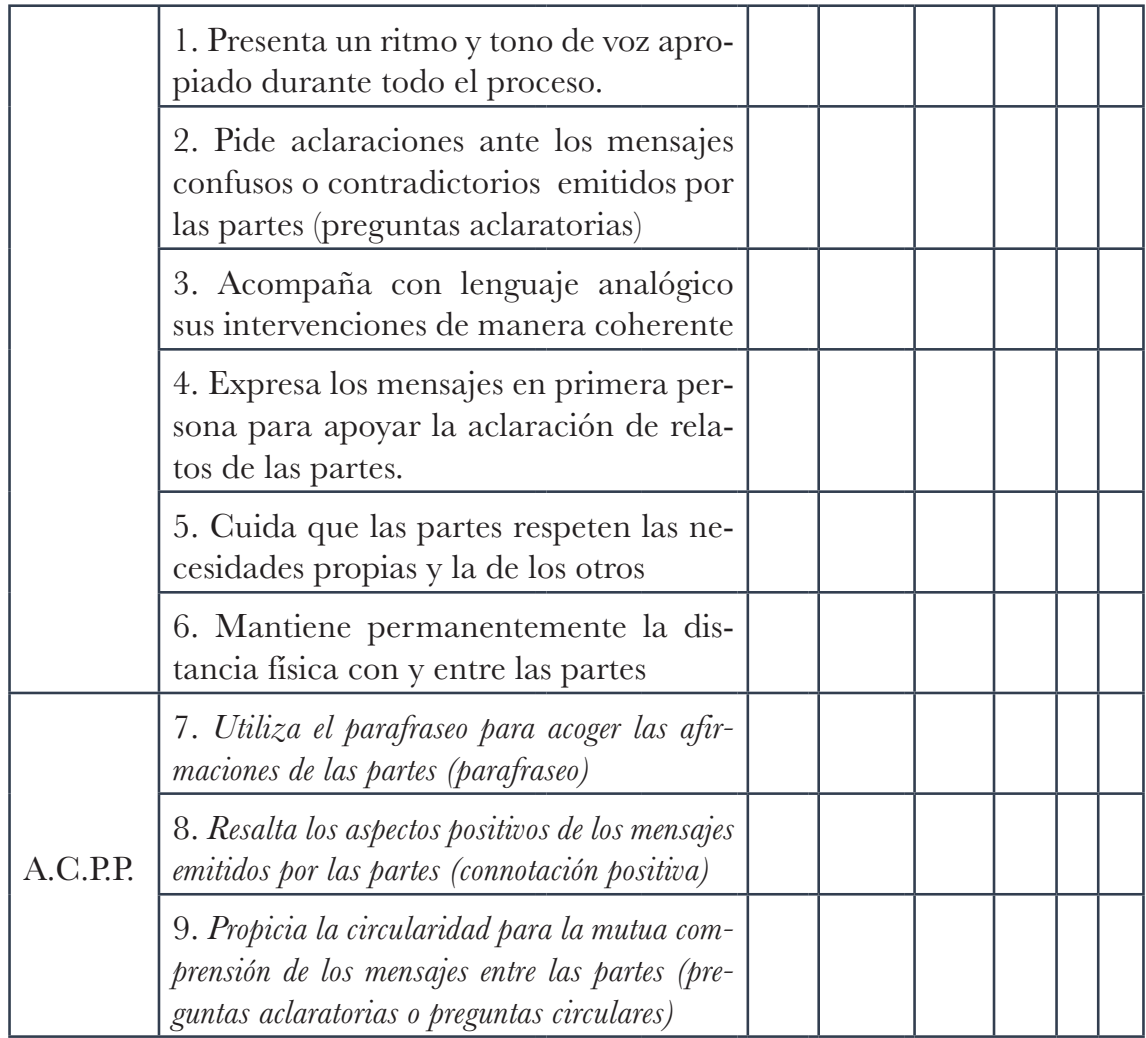


Esta revista forma parte del acervo de la Biblioteca Jurídica Virtual del Instituto de Investigaciones Jurídicas de la UNAM http://www.juridicas.unam.mx

DOI: http://dx.doi.org/10.22201/iij.24484873e.2020.158.15632

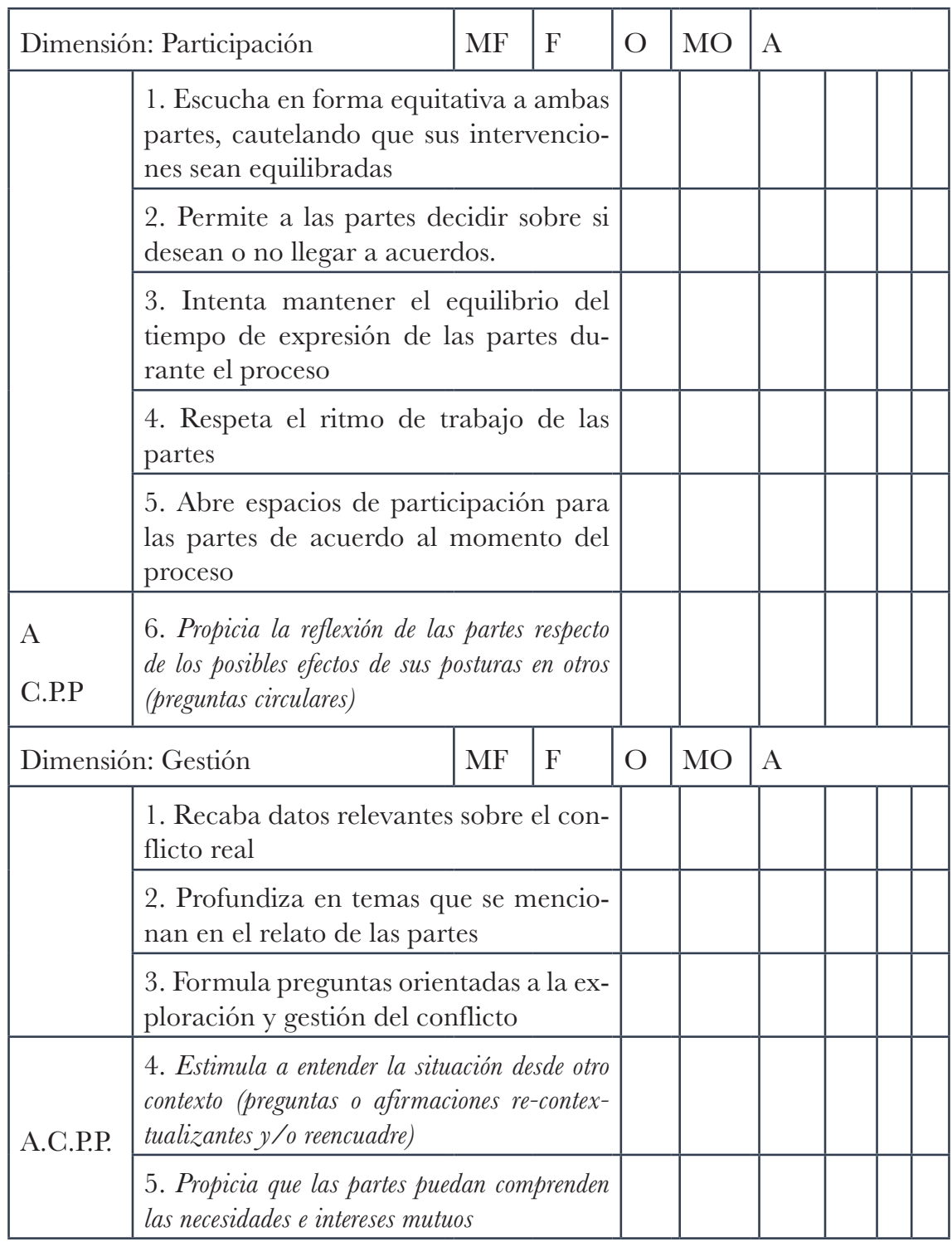

Esta obra está bajo una Licencia Creative Commons

Atribución-NoComercial-SinDerivar 4.0 Internacional, IIJ-UNAM.

Boletín Mexicano de Derecho Comparado, núm. 158, mayo-agosto de 2020, pp. 651-684. 
Esta revista forma parte del acervo de la Biblioteca Jurídica Virtual del Instituto de Investigaciones Jurídicas de la UNAM http://www.juridicas.unam.mx

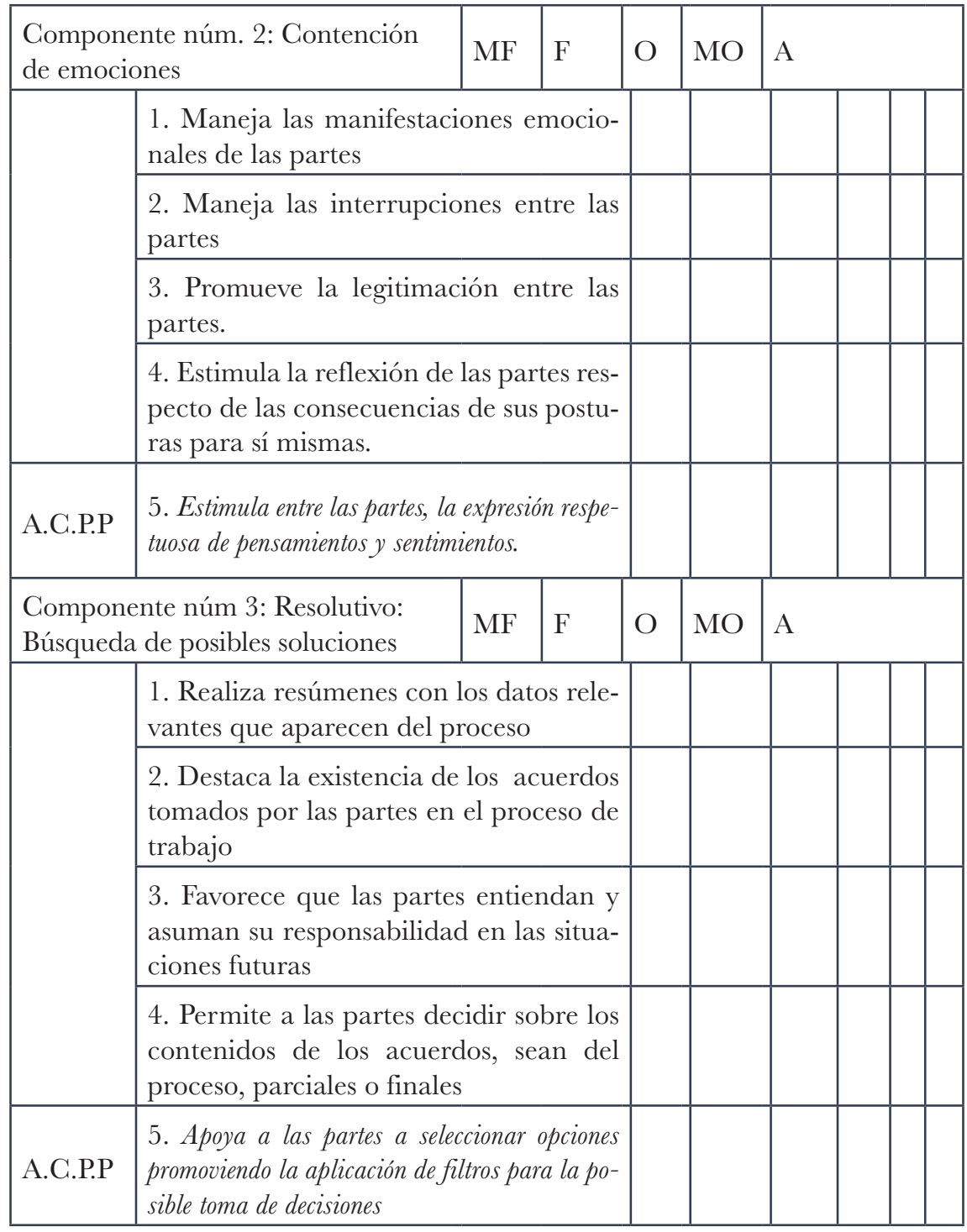

En total la pauta ECAME está compuesta por 44 ítems, los cuales presentan una estructura de escala Likert, de 5 niveles por ítems, los cuales son: ausencia, muy ocasional, ocasional, frecuente y muy frecuente. El 
mecanismo de cálculo del instrumento está distribuido por puntaje según el componente, los cuales cumplen la siguiente lógica (González, Valdebenito y Fuentealba 2018) y (González y Guevas 2020):

TABLA 1.

PORCENTAJE DE PONDERAGIÓN POR GOMPONENTES DE EGAME

\begin{tabular}{ll} 
Componentes & Ponderación \\
\hline
\end{tabular}

Componente núm. 1, Proceso de mediación $\quad 60 \%$

Componente núm. 2, Contención de emociones en los $\quad$ 15\% mediados

Componente núm. 3, Búsqueda de posibles acuerdos $\quad$ 15\% Actitudes coherentes con las políticas públicas $\quad 10 \%$

FUENTE: elaboración propia.

Estos resultados, al ser confrontados con la definición del ECAME, permite resaltar la concepción holística que dispone la metodología de calidad, mediante la observación de conductas profesionales complejas en la articulación de la teoría y práctica (González 2018).

\section{Hallazgos del estudio}

a) Los resultados obtenidos en este estudio se estructuran con base en tres objetivos, por un lado dar cuenta de los resultados generales obtenidos en la aplicación de la metodología ECAME, lo que permite generar una radiografía de la calidad de la mediación familiar en Chile, a su vez desarrollar un análisis de la consistencia interna del instrumentos mediante el coeficiente Alfa de Cronbach, del nivel en el que los ítems covarían entre sí y, por último, establecer una comparación crítica respecto de los fraseos con mayor puntaje por cada una de las dimensiones (González, Valdebenito y Fuentealba 2018). Si bien la investigación se estructura con base en tres objetivos, estos no representan elementos separados e inconexos, sino 
que más bien son insumos entre sí y, por tanto, elementos constituyente del indicador de calidad aplicado al momento de evaluar la mediación familiar.

b) En cuanto a la calidad de la mediación en Chile: el puntaje promedio obtenido en el proceso para 2018 corresponde a 74,29\%, lo que se enmarca dentro de la denominada calidad alta, ${ }^{5}$ dicho puntaje se distribuye se la siguiente forma:

TABLA 2.

PUNTAJE POR GOMPONENTES DE ECAME

\begin{tabular}{|l|l|}
\hline Componentes & Puntaje (1-100) \\
\hline Componente núm. 1, Proceso de mediación & $77,09 \%$ \\
\hline $\begin{array}{l}\text { Componente núm. 2, Contención de emociones en } \\
\text { los mediados }\end{array}$ & $67,57 \%$ \\
\hline Componente núm. 3, Búsqueda de posibles acuerdos & $73,96 \%$ \\
\hline Actitudes coherentes con las políticas públicas & $68,01 \%$ \\
\hline
\end{tabular}

FUENTE: elaboración propia.

La tabla 2 da cuenta de los puntajes para cada uno de los elementos, donde destaca el componente núm. 1 "Proceso de medicación", siendo precisamente el cual tiene mayor ponderación en el puntaje total $(60 \%)$, cabe destacar que todas las dimensiones mantienen una relación comparativa no significativamente distante (menos de 10\%), lo que a priori da cuenta de la tendencia a la homogeneidad de los puntajes independientemente del componente, dimensiones y fraseos que este tenga (González, Valdebenito y Fuentealba 2018).

Pese a ellos existen fraseos dentro de cada componente que destacan como elemento mayormente desarrollados por los y las mediadoras a nivel nacional, en el componente núm. 1 "Proceso de mediación", en la dimensión legitimidad, el aspecto mejor evaluado corresponde a si insta a las partes a decidir si desean permanecer en el proceso de mediación, con un 86.97\%,

5 Puntajes que van de $71 \%$ a $90 \%$. 
en cambio el más bajo sin ser necesariamente bajo es el relacionado con la neutralidad del mediador y el hecho de no hacer juicios de valor con $80.47 \%$.

Respecto a la dimensión de comunicación, el puntaje más alto de conductas evaluadas corresponde al ritmo y tono de voz apropiado durante todo el proceso, que obtuvo un $83.76 \%$ en cambio el más bajo es expresa mensajes en primera persona para apoyar las aclaraciones de los relatos de las partes, con un $75.29 \%$.

En la dimensión de participación el puntaje más alto es el fraseo que menciona que permite a las partes decidir si desean o no llegar a acuerdo, con un $84.63 \%$ y el elemento como menor puntaje corresponde a si respeta el ritmo de trabajo de las partes con un $81.07 \%$.

Por último, la dimensión de gestión, el elemento a destacar corresponde a la formulación de preguntas para la exploración y gestión del conflicto el cual obtiene un puntaje de $78.89 \%$, mientras que fraseo con menor evaluación es el de la profundización en temas que mencionan las parte en el relato, la que equivale a un $73.98 \%$.

En el componente núm. 2: "Contención de emociones", se destaca el fraseo de maneja las interrupciones de las partes, con $81.11 \%$, por otro lado, el punto a mejorar corresponde a promueve la legitimación entre las partes con $65.74 \%$.

En cuanto al componente núm. 3: "Búsqueda de posibles soluciones", el puntaje más alto es permite a las partes decidir sobre el contenido de los acuerdos, con $81.58 \%$ y el más bajo, realiza resúmenes con datos relevantes del proceso con $76.91 \%$ que al igual que el parafraseo en la dimensión comunicación, es de muy escaza aplicación, considerando lo relevante que son ambas técnicas para fortalecer la comunicación y comprender bien el conflicto.

Respecto de las actitudes coherentes con las políticas públicas, destacan debido a su alto puntaje, el fraseo de la promoción de la importancia de las necesidades de los $\mathcal{N N A}$, la cual obtiene un 86.97\%; por otro lado, las intervenciones que ponen en relieve la diferencia de género obtienen el menor puntaje, con $50.14 \%$. Se observa que en este elemento se encuentras los fraseos con mejor puntaje total por lo que en conjunto con el componente núm. 2 , corresponden a los elementos a potenciar, igual ocurre en las mediciones efectuadas el 2017 (González 2018 y González, Valdebenito y Fuentealba 2018). 
c) Elementos a destacar del instrumento: los resultados obtenidos a partir de la aplicación de la metodología ECAME, en conjunto con el análisis de la fiabilidad del mismo, dan cuenta de las bondades del instrumento, la coherencia del modelo ${ }^{6}$ se observa a partir del coeficiente $R 2$ que equivale a 1,000 lo que representa que el conjunto de variables explican el 100\% del puntaje, lo cual si se suma a que los 44 fraseos obtienen un nivel de significación del coeficiente de 0,000 se pude inferir que las estructuras del modelo se articula de forma correcta, dando de una relación lineal significativa (González, Valdebenito y Fuentealba 2018).

$\mathrm{Al}$ tomar los 8 fraseos con mayor peso relativo se observa que el componente núm. 2 corresponde al elemento con mayor relevancia dentro del puntaje total obtenido, lo que representa 0.281 puntos en el coeficiente beta, los ítems del componente en promedio un puntaje de 0.70 puntos.

TABLA 4.

FRASEOS GON MAYOR IMPORTANCIA EN LA CORRELAGIÓN

\begin{tabular}{|l|l|l|}
\hline Fraseos & $\begin{array}{l}\text { Componente } \\
\text { / Dimensión }\end{array}$ & $\begin{array}{l}\text { Coeficientes } \\
\text { estandarizados }\end{array}$ \\
\cline { 2 - 3 } & Beta \\
\hline Promueve la legitimación entre las partes. & 2 & 0,081 \\
\hline $\begin{array}{l}\text { Expresa los mensajes en primera persona } \\
\text { para apoyar la aclaración de relatos de las } \\
\text { partes. }\end{array}$ & $1-2$ & 0,080 \\
\hline $\begin{array}{l}\text { Maneja las manifestaciones emocionales de } \\
\text { las partes }\end{array}$ & 2 & 0,073 \\
\hline $\begin{array}{l}\text { Profundiza en temas que se mencionan en } \\
\text { el relato de las partes }\end{array}$ & $1-4$ & 0,066 \\
\hline
\end{tabular}

6 El modelo se compone de los 44 fraseos dentro de la metodología de evaluación de la calidad de la medicación ECAME. 


\begin{tabular}{|l|l|l|}
\hline $\begin{array}{l}\text { Estimula la reflexión de las partes respecto } \\
\text { de las consecuencias de sus posturas para sí } \\
\text { mismas. }\end{array}$ & 2 & 0,065 \\
\hline $\begin{array}{l}\text { Realiza resúmenes con los datos relevantes } \\
\text { que aparecen del proceso }\end{array}$ & 3 & 0,064 \\
\hline Maneja las interrupciones entre las partes & 2 & 0,062 \\
\hline $\begin{array}{l}\text { Destaca la existencia de los acuerdos } \\
\text { tomados por las partes en el proceso de } \\
\text { trabajo }\end{array}$ & 3 & 0,062 \\
\hline
\end{tabular}

FUENTE: elaboración propia.

La tabla 4 muestra los elementos con mayor importancia respecto del modelo, en este sentido se destaca el ítem de promueve la legitimación entre las partes dado que corresponde al elemento con mayor peso, pese a la importancia del fraseo, este obtiene el menor puntaje de la dimensión, dado que requieren de técnicas más complejas y, por tanto, más experiencia del mediador.

Que el componente núm. 2, de contención de emociones sea el de mayor relevancia en el instrumento es coherente con los estudios realizados por el MINJU sobre la percepción usuaria sobre la mediación familiar, que valora que en su proceso se trabajen contenidos más allá del ámbito de los acuerdos (González 2018), puesto que éstos requieren fortalecer los vínculos comunicacionales y emocionales en la familia (Roché Cisneros, J. A. 2011), para lo que necesita de un tercero con conocimientos teóricos y técnico-metodológicos, que le permita al usuario ampliar su visión del conflicto (Gavrielides 2015), para empoderarse, participar activamente y ejercer plenamente sus derechos.

Así podemos observar en el siguiente cuadro, que la mayor o menor calidad que posee el mediador no influye en obtener o no a acuerdo en el proceso de mediación (González 2018). El que puede ser igual de útil y satisfactorio para las partes, aunque no se logre un acuerdo, porque los objetivos del proceso se focalizan más bien a contribuir a fortalecer la relación entre las partes y entender las necesidades que se encuentras tras el conflicto. 
GRÁFICA 1.

TERMINA GON O SIN AGUERDO LA SESIÓN SEGÚN CATEGORÍAS DE CALIDAD ECAME

\section{ÍNDICE ECAME Y ACUERDO}

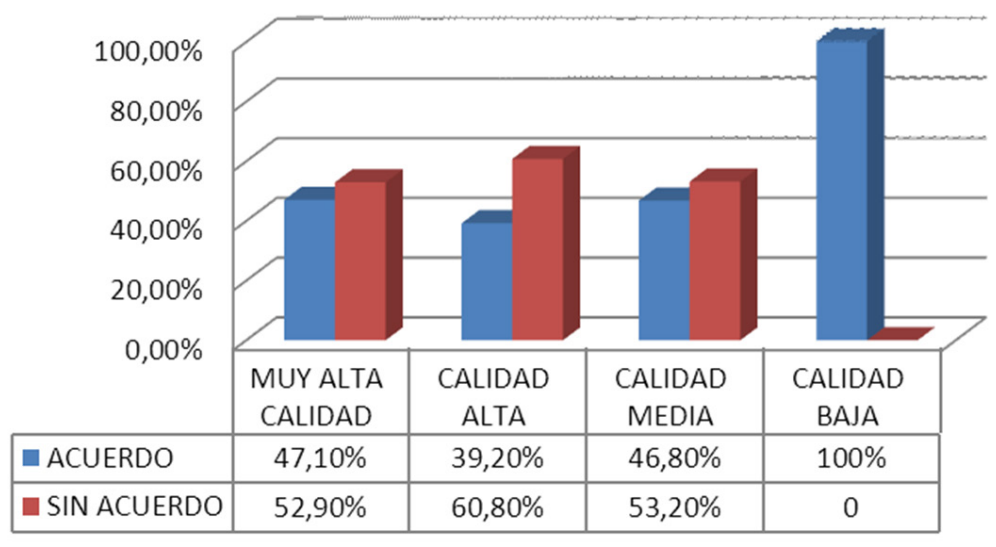

FUENTE: elaboración propia.

Otro aspecto que si puede influir en la calidad del proceso de mediación es su duración, es así como en las sesiones cuya extensión es mayor mostraron una mejor evaluación en el índice de calidad con 75.6\% en calidad alta y muy alta (duración de 61 a 90 minutos, el 50.4\% se ubicó en calidad alta, un $25.2 \%$ en calidad muy alta), en cambio las sesiones que no se prolongaron más allá de los 30 minutos se evaluaron mayoritariamente en calidad media, 71.4\%. Es así como el estándar de calidad baja tiende a descender a medida que aumenta la duración de las sesiones, desapareciendo sobre 90 minutos, igual ocurrió en el estudio de González (2018) y de González, Valdebenito y Fuentealba (2018), realizado en 2017.

En contraste con el componente núm. 2 se observa que los ítems correspondientes al ACPP son los que obtiene menor importancia del total de modelo, lo que representa un total de 0.250 en el coeficiente beta, es decir, en promedio sus fraseos equivalen a 0,013 puntos de la ecuación de regresión, lo que ocurrió en forma similar en el estudio (González, Valdebenito 
y Fuentealba 2018). En este sentido se destaca el ítem de promueve el dialogo sobre la participación de ambos padres en la crianza y desarrollo de los hijos/as (coparentalidad) dado que corresponde al elemento con menor peso, no obstante, este elemento representa uno de los fraseos con mejor evaluación dentro del componente.

Se observa que dentro del modelo propuesto por la metodología ECAME existen elementos con mayor y menor importancia, no obstante, no existen relación lineal entre el puntaje de los ítems y el peso de cada uno de ellos (coeficiente de correlación $=0$ ).

Así, este sistema de supervisión y selección, por medio de la sostenida aplicación de una metodología de desarrollo experimental cuyos procesos e instrumentos están en permanente actualización (Sallard 2009), con un sistema de enseñanza aprendizaje entre pares, lo que permite tener grandes expectativas con los resultados futuros de los procesos de mediación familiar licitada y la mejora continua de este servicio en el ámbito público en Chile (González y Guevas 2020).

Según el estudio de González y Cuevas (2020) como la mediación en Iberoamérica es un mecanismo de política pública importante en materia de derecho de familia (Preyer 2016), se requiere analizar cuáles son los componentes más esenciales en que debe centrarse la supervisión y formación en técnicas de los mediadores familiares licitados, con el objeto de mejorar la calidad del servicio que se presta a la comunidad (Sallard 2009). Investigación que concluye que los principales elementos que miden la calidad en esta materia son relativos al componente de: 1. Legitimidad, 2. Comunicación, 3. Participación, 4. Acogida y contención de emociones y 5 . Teniendo como parámetro durante todo el proceso la variable de género, se debe observar que los designados con los números 3, 4 y 5 presentan mayor complejidad en su desarrollo por parte de los mediadores (González y Cuevas 2020).

La legitimidad, en general, es un aspecto en el que casi todos los mediadores tienen buen desempeño y que señala la relación con la obligación del mediador de explicar correctamente que es la mediación: sus características, el rol del mediador, los principios que la sustentan (voluntariedad, imparcialidad, equilibrio de poderes, interés superior del niño/a y adolescente y las condiciones de contexto (tales como indicar que es adecuado obtener asesoría jurídica, normas de comportamiento en la sesión) y alguna información jurídica que la regula (como temas relativos a 
los alimentos provisorios, prohibición de mediar cuando hay acciones de violencia intrafamiliar vigentes, entre otras) (González y Cuevas 2020) y (Briz 2020).

Uno de los ítems a evaluar más ligados a las relaciones de familia son: si el mediador usa un enfoque de género, si promueve que los adultos responsables consideren las necesidades de los niños, niñas y adolescentes, si posibilitan la participación de NNA en el proceso de mediación conforme a su desarrollo integral y si promueve el dialogo sobre la participación de ambos padres en la crianza y desarrollo de los hijos/as (co-parentalidad) (Briz 2020) y (Lloveras et al. 2010).

En cuanto a las intervenciones que ponen en relieve las diferencias de género que es una categoría construida social y culturalmente, que viene a definir qué se entiende en cada sociedad y cultura por lo femenino y masculino, que delimita qué valores, conductas y expectativas deben ser propias de los hombres y cuáles de las mujeres (Espejo 2016). Así, en nuestra sociedad en la que las relaciones entre sexos están jerarquizadas y los valores dominantes son masculinos, regulando el género, la asignación de capacidades, roles, expectativas y pautas esperadas de comportamiento de cada sexo (Lombardo 2003).

Se entiende que el sexismo es un limitador natural que reduce las posibilidades de las personas para desarrollar sus capacidades y, por tanto, supone un lastre para la libertad individual y colectiva (Sivak y Wiater 1997) y (Russell y Radford 2017). La mediación puede servir para aminorar estereotipos de género, que son creencias sobre las características de los roles típicos que los hombres y las mujeres tienen que desarrollar en una cultura social. Mecanismo que ayuda a cuestionarse los estereotipos masculinos y alexitimia entendida como la incapacidad para verbalizar afectos" (Sivak y Wiater 1997) y (González y Cuevas 2020).

Respecto a las habilidades comunicativas' del mediador, el instrumento evalúa la capacidad del mediador de establecer un clima de confianza y un puente de comunicación entre las partes usando técnicas como el lenguaje analógico, expresar mensajes en primera persona y el parafraseo (González y Cuevas 2020).

El parafraseo: es una técnica que ayuda a entender e interpretar las expresiones, hechos y actos de las personas de una forma distinta a la que habían venido comunicando hasta ahora, eliminando descalificaciones, agresiones, sustantivaciones y generalizaciones que impedía entender el 
conflicto con un enfoque de necesidades de los involucrados (Briz 2018). El parafraseo y los resúmenes dan contexto a las peticiones de las partes y orientan el estado de avance del proceso. Su uso permite sumar a continuación otras técnicas como preguntas cerradas, abiertas, indagatorias, reflexivas, hipotéticas y circulares, lo que facilita abrir el conflicto e ir transformando las posiciones en necesidades de las partes (González y Cuevas 2020). Para Bernaldo de Quirós (2019) consiste en cambiar una forma de presentación conservando la significación de fondo. Para poder cambiar la forma del texto es necesario utilizar otras palabras que, con significado similar, representen el mismo contenido (Szlapelis 2018) y (Sallard 2009).

El objetivo de esta técnica es ganarse la confianza de las partes, evidenciando que las escucha activamente y que comprende lo que el otro dice; asegurarse de que ha comprendido exactamente lo dicho, e identificar los puntos centrales del asunto que se trata (Szlapelis 2018) y (González y Cuevas 2020).

Respecto a la participación, pretende crear un clima de confianza, equilibrar el poder y lograr igualdad entre las partes, por medio de una intervención equilibrada de éstas, para lo que se respeta el ritmo de trabajo de las partes; abre espacios de participación de acuerdo con el momento del proceso y propicia la reflexión de las partes respecto de los posibles efectos de sus posturas en otros con preguntas reflexivas y circulares (González y Cuevas 2020).

Las intervenciones circulares: permiten al mediador dar circularidad al conflicto, hacen ponerse a las partes en el lugar de la otra, de hijos o terceros. Nos ayudan a indagar en la queja de nuestros usuarios de una forma inherentemente sistémica (Ochoa 1995).

Respecto de la contención de emociones: son conductas o habilidades que despliega el mediador referidas a contener las agresiones de corte psicológico y habilidad emocional (Briz 2018), se utilizan técnicas como la identificación y expresión de la emoción y la re-significación de ésta, dándole un contexto, temporalidad y circunstancias en que se manifiesta (González y Cuevas 2020), con el objeto de ser entendida adecuadamente y que la otra parte pueda empatizar con ella.

También la legitimación, es una técnica muy importante, que intenta que las partes se reconozcan mutuamente algunos valores, virtudes o actitudes personales, lo que crea un clima de entendimiento que facilita 
acuerdos (González y Cuevas 2020). La legitimación se refiere al título de poder que necesita ser regulado para volverse legítimo (Branda, Corina 2019). En el campo de la mediación, las personas gozan de legitimidad cuando sus actitudes, argumentaciones o pretensiones, se apoyan en razones o motivos socialmente válidos (Branda, Corina 2019). Según Diez y Tapìa (2005), se sustenta en dos componentes claves de la mediación, una tiene su origen en el modelo de Harvard, la separación de las personas del problema y la otra en la comunicación que ejerce impactos en la interacción humana.

En cuanto a la búsqueda de posibles acuerdos: se refiere a como el mediador va fortaleciendo la reflexión entre las partes para la posible toma de decisiones respecto del conflicto que los trae a mediación. Se emplean técnicas como la lluvia de ideas, múltiples opciones y aplicación de filtros a los acuerdos de las partes para que estos sean sustentables, mediante técnicas como: agente de realidad y abogado del diablo, entre otras (González y Guevas 2020).

Finalmente, las actitudes coherentes con las políticas públicas son aquellas que abordan elementos como el enfoque de género (Lombardo E. 2003), aspectos de interculturalidad, identidad sexual, violencia intrafamiliar, presencia de los niños, niñas y adolescentes en la mediación (Villacampa C. 2012), co-parentalidad (Latrop, F. 2013) y derechos de los niños, niñas y adolescentes (Barcia R. 2013), que sus ítems no correlacionaron numéricamente en ninguno de los componentes del instrumento, pero que fueron incluidos por su importancia en el proceso y haber sido validados por expertos, cuyo puntaje no se promedia con los componentes y pueden cambiarse con el tiempo conforme a las orientaciones de las políticas públicas (González y Cuevas 2020).

\section{COnClusiones}

1. De lo expuesto anteriormente se puede concluir que: el Estado de Chile cuenta con una política pública que permite optimizar la calidad de los servicios de mediación familiar licitados, la que contempla procesos de selección, supervisión y evaluación de la calidad de la mediación familiar estandarizados, confiables y validados con una metodología experimental, participativas y de aprendizaje-acción, que se aplican anual- 
mente a nivel nacional, desde 2011 a la fecha 2020, lo que ha aportado al mejoramiento continuo de la calidad del servicio de mediación, la que sería útil de aplicar en otros países de Latinoamérica con los mismos fines.

2. El valor alcanzado por el IGGM en el país, lo sitúan en el tramo de "calidad alta", cuya tendencia va en alza, lo que se explica, entre otras razones, porque gran parte de los mediadores fueron supervisados en forma anual, entendiendo que la aplicación de este instrumento es un buen método de aprendizaje para las prácticas mediadoras, dado que da la posibilidad al mediador de revisar su actuación por medio de la grabación del proceso y aprender a través de la retroalimentación que le da el par evaluador.

La concentración en valores altos alcanzados en este estudio, también se debe a que el grupo de mediadores licitados que tiene contrato con el Estado, mantiene una práctica habitual de un gran número de mediaciones, al ser permanentemente sujetos a evaluaciones, supervisiones y capacitaciones por la Unidad de Mediación del Ministerio de Justicia y Derechos Humanos, permitiéndoles disponer de una considerable cantidad de conocimientos, herramientas procedimentales y técnicas para un buen estándar de desempeño.

3. Ahora bien, en cuanto al alza en el puntaje de mediadores que han entrado recién al sistema licitado se puede explicar porque han subido los estándares de exigencia que se imponen al ingreso al sistema licitado, aplicando este mismo instrumento ECAME para la selección de los nuevos mediadores.

4. Los tres componentes, sus dimensiones y las actitudes coherentes con las políticas públicas, que presenta la pauta ECAME utilizada en las supervisiones, corresponden a criterios mínimos de contenido y relacionales que se deben desarrollar en un proceso de mediación familiar y que deben estar presentes en las conductas observadas de los mediadores, por lo tanto, son aplicables a todos los países de Latinoamérica que tienen una cultura y legislación similar en esta materia.

5. La metodología cumple los estándares de fiabilidad y significancia requerida para representar un modelo articulado de medición de la calidad de la mediación familiar.

6. El peso relativo de cada ítem contenido en cada componente, no presenta una relación con el puntaje que se obtenga en éste, no obstante, existen elementos que independientemente de puntaje obtenido tiene ma- 
yor o menor peso dentro del modelo, los cuales son, principalmente, los relacionados con promover la legitimación entre las partes, expresar los mensajes en primera persona, parafrasear para apoyar la aclaración de relatos de las partes, la contención y resignificación de las emociones, el enfoque de género, la importancia que da el mediador a la participación de niños/as y adolescentes y permitir abrir el abanico de recursos y oportunidades que poseen las partes para el logro de sus necesidades mutuas.

\section{BIBLIOGRAFÍA.}

AGuña San Martín, M. 2011. Efectos jurídicos del divorcio. Santiago. Abeledo Perrot y Thompson Reuters.

Aguilar IbáÑez, M. J. 1994. Introducción a la supervisión. Buenos Aires. Editorial Lumen.

BARGIA LeHMANN, R. 2013. "Facultades y derechos compartidos respecto de los hijos: una mirada desde el derecho comparado". Revista de Derecho. La Serena. Universidad Católica del Norte, año 20, núm. 1.

BelofF, M. 2010. "Comportamiento humano y justicia: los equipos multidisciplinarios en las normas internacionales de protección de los derechos de la infancia y su impacto en las legislaciones nacionales latinoamericanas". GARCíA, Eric (coord.). Fundamentos de psicología jurídica y forense. México Oxford University Press, 261- 277.

BERnALDO DE QUIRós, Catalina. 2019. El parafraseo y la reformulación en mediación, publicación digital. Sotogrnade.

Brandoni, F. 2011. Hacia una mediación de calidad. Buenos Aires. Paidós.

BRANDA, Corina. 2019. Revista de Mediación, núm. 8, vol. 12, núm. 2. España.

Briz Clariget, María José. 2018. "La mediación y el síndrome de alineación parental". Revista de Mediación, Madrid, 2-56.

CADEM. 2017. "Diseño, Aplicación y Análisis de Encuesta de Satisfacción de Usuarios/as del Sistema Nacional de Mediación Familiar". https:// wrere.mediacionchile.cl/media/2017/03/Informe-Final-Mediaci\%C3\%B3nFamiliar-CADEM_VF.pdf.

Carvajal, L. 2013. Desarrollo experimental. wwrw.lizardo-carvajal.com/desarrollo-experimental/ (consultado el 17 de diciembre de 2019). 
Correa, P. 2014. "La experiencia de la mediación familiar en Chile. Elementos para una política pública futura". Revista Chilena de Derecho y Ciencia Política, mayo- agosto, ISSN 0719-2150, vol. 5, núm. 2, 111-138, doi.org/10.4067/S0718-65682017000300271.

Gervantes, V. 2005. Interpretaciones del coeficiente alpha de Cronbach. Colombia. Universidad Nacional de Colombia.

DiEz, Francisco y TAPIA, Gachi. 2005. Herramientas para trabajar en mediación. Paidós Iberica S. A.

Espejo Castagnoli, Paola. 2016. "Género, estereotipos, alexitimia y violencia conyugal. Análisis psicosocial”. Revista de Mediación Familiar Chilena. Ministerio de Justicia.

Fernández, C. y Cols, A. 2013. "Calidad de la mediación. Teoría versus práctica”. Revista Momento, Serie Ciencias Sociales, año 28, núm. 5.

FOLGER, Joseph. 2006. La promesa de la mediación, Barcelona, Gránica.

García Petit, M. y Aguilera Lillo, G. 2009. "Tres problemas jurídicos asociados al control y supervisión de los mediadores familiares". Revista CREA. Temuco. Universidad Católica de Temuco, 101-115.

Gavrielides, T. 2015. Restorative Fustice. The Library of Essays on Fustice. Londres. Ashgate Publishing.

GonzÁlez RAmíREZ, Isabel Ximena. 2018. "La calidad de la mediación en Chile". Revista de Derecho Privado. Externado de Colombia: 369-390. ORCID 0000-0001-6845-8198.

GonzÁlez Ramírez, Isabel Ximena, Valdebenito Larenas, Caterine y Fuentealba MARTinez, Soledad. 2018. "Un novedoso instrumento para evaluar la calidad de la mediación de conflictos jurídicos familiares en Chile". Revista Caldas, Bogotá: 65-87.

GonzÁlez Ramírez, Isabel Ximena y Guevas Campos, Bastian. 2020. "La influencia de las variables género, lenguaje y legitimación en la calidad de la mediación familiar". Revista de Mediación, núm. 13: 30. España.

Hernández-Sampieri, R. 2003. Metodología de la investigación. México. McGraw-Hill.

Informes e instructivos de la Unidad de Mediación. 2017. wrere.mediacionchile.cl.

Kerlinger, F. 2011. Investigación del comportamiento. México. McGrawHill-Interamericana Editores. 
LATHROP, F. 2013. "Nueva institucionalidad de infancia y adolescencia en Chile", Aportes de la sociedad civil y del mundo académico. Santiago. ORCID 0000-0001-8324-5908.

LeHtinen, U. y Lehtinen, JR. 1982. "Service Quality: A Study of Quality Dimensions". The Services Industries fournal, vol. 2 núm. 3. https:// technopreneurship.files.wordpress.com/.../dra (consultado en noviembre de 2017).

LlOVERAS, N. et al. 2010. Los derechos de los niños, niñas y adolescentes. Buenos Aires, Ediciones Alveroni.

LOMBARDO, E. 2003. "El Mainstreaming de género en la Unión Europea". Revista Aequalitas, Furídica de Igualdad de Oportunidades entre Mujeres y Hombres, vol. 10- 15, mayo-diciembre: 6-11. http://pendientedemigracion. ucm.es/info/mageeq/documentos/Art_MainstreamingUE.pdf (consultado en julio de 2020).

LÓPEZ, Ema. 2012. Mediación y calidad. http://wrere.cambrabcn.org/documents/1533402/1541141/GTM5_TRIBUNA_Mediacion+y+calidad_ Emma+Lopez Ok.pdf?version=1.0 (consultado en agosto de 2020).

MuÑOz LEÓN, F. 2015. “¿Hacia la academización de las facultades de derecho en Chile? Un análisis teórico y comparado del conflicto de las profesiones". Revista de Derecho, vol. XXVII. Valdivia, 81-95.

OCHOA DE ALDA, Inmaculada. 1995. Enfoques en terapia familiar sistémica: la entrevista circular como intervención. Barcelona. Pedido Editorial.

Preyer, G. 2016. "Una interpretación de la globalización: un giro en la teoría sociológica". Revista Mexicana de Ciencias Politicas y Sociales. México. Universidad Nacional Autónoma de México, Nueva Época, año LXI, núm. 226, enero- abril: 61-88. ORCID 0000-0002-1410-686.

RAWLS, J. 2002. La justicia como equidad: una reformulación, trad. de Andrés de Francisco. Barcelona. Paidós. ORCID 0000-0002-5976-5206.

RoGhÉ Cisneros, J. A. 2011. La mediación y sus principios. wrere.imet.gob.mx/ arts_dirgral/art004.htm (consultado en diciembre de 2018).

Russell, E. H. y Caputi J. 1992. Femicide: Sexist terrorism against women.

Russell D., RADFORD J. 2017. Femicide, The Politics of Woman Killing. http://wrerr.dianarussell.com/f/femicde\%28small\%29.pdf .

SALLARD, S. 2009. Mediación, supervisión y contención. Una visión tridimensional. México. Universidad de Sonora.

SIVAK, R. y WiATER, A. 1997. Alexitimia, la dificultad para verbalizar afectos. Teoría y clínica. Buenos Aires. Paidós.

Esta obra está bajo una Licencia Creative Commons Atribución-NoComercial-SinDerivar 4.0 Internacional, IIJ-UNAM. Boletín Mexicano de Derecho Comparado, núm. 158, mayo-agosto de 2020, pp. 651-684. 
SzlaPELIS, Daniel. 2018. El parafraseo Plottier. Provincia del Neuquén. Argentina.

STEIN, A. 2015. "Contra la prueba libre". Revista de Derecho, vol. XXVII, Valdivia: 467-480.

Universidad de Concepción. 2006. Estudio Calidad del Servicio de Mediación Licitado por el Ministerio de Justicia, Santiago, Ministerio de Justicia de Chile. http://wrwemediacionchile.cl/MinfusPubl/Sitio/pub_estadisticas.aspx (consultado en enero de 2018).

VILlaCAMPA ESTIARTE, C. 2012. "La justicia restaurativa en los supuestos de violencia doméstica y de género". La Justicia Restaurativa, desarrollo y aplicaciones. Granada. Comares. ORCID 0000-0002-1791-8788. 